University of Wollongong

Research Online

Australian Institute for Innovative Materials -

Papers

Australian Institute for Innovative Materials

$1-1-2015$

Significantly enhanced critical current density in nano-MgB2 grains rapidly formed at low temperature with homogeneous carbon doping

Yongchang Liu

Tianjin University, Nankai University

Feng Lan

Tianjin University

Zongqing $\mathrm{Ma}$

University of Wollongong, zqma@uow.edu.au

Ning Chen

Tianjin University

Huijun Li

University of Wollongong, huijun@uow.edu.au

See next page for additional authors

Follow this and additional works at: https://ro.uow.edu.au/aiimpapers

Part of the Engineering Commons, and the Physical Sciences and Mathematics Commons

Research Online is the open access institutional repository for the University of Wollongong. For further information contact the UOW Library: research-pubs@uow.edu.au 


\title{
Significantly enhanced critical current density in nano-MgB2 grains rapidly formed at low temperature with homogeneous carbon doping
}

\begin{abstract}
High performance $\mathrm{MgB}_{2}$ bulks using carbon-coated amorphous boron as a boron precursor were fabricated by $\mathrm{Cu}$-activated sintering at low temperature $\left(600^{\circ} \mathrm{C}\right.$, below the $\mathrm{Mg}$ melting point). Dense nano$\mathrm{MgB}_{2}$ grains with a high level of homogeneous carbon doping were formed in these $\mathrm{MgB}_{2}$ samples. This type of microstructure can provide a stronger flux pinning force, together with depressed volatility and oxidation of $\mathrm{Mg}$ owing to the low-temperature $\mathrm{Cu}$-activated sintering, leading to a significant improvement of critical current density $\left(J_{C}\right)$ in the as-prepared samples. In particular, the value of $J_{C}$ for the carboncoated $\left(\mathrm{Mg}_{1.1} \mathrm{~B}_{2}\right) \mathrm{Cu}_{0.05}$ sample prepared here is even above $1 \times 10^{5} \mathrm{~A} \mathrm{~cm}^{-2}$ at $20 \mathrm{~K}, 2 \mathrm{~T}$. The results herein suggest that the combination of low-temperature Cu-activated sintering and employment of carbon-coated amorphous boron as a precursor could be a promising technique for the industrial production of practical $\mathrm{MgB}_{2}$ bulks or wires with excellent $J_{c}$, as the carbon-coated amorphous boron powder can be produced commercially at low cost, while the addition of $\mathrm{Cu}$ is very convenient and inexpensive.
\end{abstract}

\section{Keywords}

carbon, homogeneous, nano, density, current, critical, enhanced, temperature, low, doping, formed, significantly, rapidly, grains, mgb2

\section{Disciplines}

Engineering | Physical Sciences and Mathematics

\section{Publication Details}

Liu, Y., Lan, F., Ma, Z., Chen, N., Li, H., Barua, S., Patel, D., Shahriar, M., Hossain, A., Acar, S., Kim, J. \& Dou, S. Xue. (2015). Significantly enhanced critical current density in nano-MgB2 grains rapidly formed at low temperature with homogeneous carbon doping. Superconductor Science and Technology, 28 (5), 055005-1-055005-7.

\section{Authors}

Yongchang Liu, Feng Lan, Zongqing Ma, Ning Chen, Huijun Li, Shaon Barua, Dipakkumar Patel, Md S. Hossain, S Acar, Jung Ho Kim, and S X. Dou 


\section{Significantly enhanced critical current density in nano $\mathrm{MgB}_{2}$ grains formed at}

\section{low temperature with homogeneous carbon doping}

Yongchang $\mathrm{Liu}^{1}$, Feng Lan ${ }^{1}$, Zongqing Ma ${ }^{1,2 *}$, Ning $\mathrm{Chen}^{1}$, Huijun $\mathrm{Li}^{1}$, Shaon Barua ${ }^{2}$, Dipak

$$
\text { Patel }^{2} \text {, M. Shahriar Al Hossain², S. Acar }{ }^{3} \text { Jung Ho Kim², Shi Xue Dou }{ }^{2}
$$

1. Tianjin Key Laboratory of Composite and Functional Materials, School of Materials Science \& Engineering, Tianjin University, Tianjin 300072, People's Republic of China

2. Institute for Superconducting and Electronic Materials, University of Wollongong

3. Pavezyum Kimya San. Dis Tic. Ltd. Sti, Tuzla - Ístanbul - Turkey

\section{Abstracts}

High performance $\mathrm{MgB}_{2}$ bulks using carbon-coated amorphous boron as boron precursor were fabricated by $\mathrm{Cu}$-activated sintering at low temperature $\left(600^{\circ} \mathrm{C}\right.$, below the $\mathrm{Mg}$ melting point). Dense nano-MgB 2 grains with a high level of homogeneous carbon doping were formed in these $\mathrm{MgB}_{2}$ samples. This type of microstructure can provide a stronger flux pinning force, together with depressed volatility and oxidation of $\mathrm{Mg}$ owing to the low-temperature $\mathrm{Cu}$ activated sintering, leading to the significant improvement of critical current density $\left(J_{c}\right)$ in the as-prepared samples. In particular, the value of $J_{c}$ for the carbon-coated $\left(\mathrm{Mg}_{1.1} \mathrm{~B}_{2}\right) \mathrm{Cu}_{0.05}$ sample prepared here is even above $1 \times 10^{5} \mathrm{~A} / \mathrm{cm}^{2}$ at $20 \mathrm{~K}, 2 \mathrm{~T}$. The results herein suggest that the combination of low-temperature $\mathrm{Cu}$ activated sintering and employment of carbon-coated amorphous boron as precursor could be a promising technique for the industrial production of practical $\mathrm{MgB}_{2}$ bulks or wires with excellent $J_{c}$, as the carbon-coated amorphous boron powder can be produced commercially at low cost, while the addition of $\mathrm{Cu}$ is

\footnotetext{
* Corresponding author Tel \& Fax: 0086-22-87401873 E-mail: mzq0320@163.com
} 
very convenient and inexpensive.

Keywords: carbon coated boron; $\mathrm{MgB}_{2}$; critical current density

\section{Introduction}

The intermetallic compound $\mathrm{MgB}_{2}$ with the transition temperature $\left(T_{c}\right)$ of $39 \mathrm{~K}$ has been the focus of worldwide attention, due primarily to its potential for practical applications [1]. Its electrical application is largely determined by the current carrying capability, i.e. the critical current density $\left(J_{c}\right)$ of the superconductor at the application temperature. Although considerable progress has been made in the fabrication and performance of $\mathrm{MgB}_{2}$ to date [2], the critical current density in $\mathrm{MgB}_{2}$ is still below optimized material [3].

As is well known, flux pinning and grain connectivity are the critical factors determining the performance of $J_{c}$ in the Type II superconductors. A significant improvement might be achieved in $J_{c}$ of $\mathrm{MgB}_{2}$ if one technique could enhance the flux pinning strength and increase the grain connectivity at the same time. Low-temperature (below the melting point of $\mathrm{Mg}$ ) sintering, which was developed in recent years, is potentially such a technique [4-6]. Low sintering temperature can significantly depress volatility and oxidation of $\mathrm{Mg}$, which leads potentially to improved connectivity between the $\mathrm{MgB}_{2}$ grains. In addition, sintering at low temperature can also prevent $\mathrm{MgB}_{2}$ grain coarsening, allowing refined grains to be obtained, which enhances grain-boundary pinning. Both factors are responsible for the improvement of critical current density in samples sintered at low temperatures 
compared to those processed above the melting point of Mg. The reaction between magnesium and boron at low temperature, however, generally takes a very long time to form the complete $\mathrm{MgB}_{2}$ phase due to the low diffusion rate of atoms in the solid state reaction type below the melting point of $\mathrm{Mg}[4,7]$. Many efforts have been made, including ball milling, the usage of nano-Mg precursor, and metal doping, to lower the formation temperature and shorten the processing time of $\mathrm{MgB}_{2}$ [8-16]. Among these methods, metal doping as $\mathrm{Ag}, \mathrm{Sn}, \mathrm{Bi}$, Se, Te or $\mathrm{Mg} 2 \mathrm{Cu}$ were used [11, 14, 13 and $15(\mathrm{Mg} 2 \mathrm{Cu}), 16]$, as well as minor $\mathrm{Cu}$ doping $[12,17]$, was proved to be the most convenient, effective, and inexpensive way to improve the formation of $\mathrm{MgB}_{2}$ during the low-temperature reaction. In our previous studies [18-20], the mechanism behind the accelerated phase formation of $\mathrm{MgB}_{2}$ by $\mathrm{Cu}$ addition was also investigated based on the activated sintering theory [21].

Although $\mathrm{Cu}$ addition is the most effective activator during the low-temperature sintering of $\mathrm{MgB}_{2}$ superconductor, the improvement in $J_{\mathrm{c}}$ (in particular, at high magnetic fields) for $\mathrm{MgB}_{2}$ samples prepared by $\mathrm{Cu}$-activated sintering at low temperature still cannot meet the requirements of applications, and more efforts are needed to further enhance $J_{\mathrm{c}}$. On the other hand, it is now well established that carbon doping can obviously improve the $J_{\mathrm{c}}$ performance of $\mathrm{MgB}_{2}$ at high fields by the substitution of carbon onto boron lattice sites [22, 23]. Based on this background, a low-cost and practical method for fabricating $\mathrm{MgB}_{2}$ superconductors with significantly improved $J_{\mathrm{c}}$ may be obtained potentially by combining the advantages of Cu-activated sintering at low temperature and carbon doping. Evidently, choosing the 
appropriate approaches that can effectively introduce carbon doping during the low temperature sintering is fundamental to the successful application of this method. Based on previous studies [2, 24-28], not all carbon doping techniques that are effective in the high-temperature synthesis process of $\mathrm{MgB}_{2}$ are still available in their low-temperature synthesis process. It is proposed that only those approaches that are able to release highly active $\mathrm{C}$ before the commencement of solid-solid reaction between $\mathrm{Mg}$ and B can lead to the effective carbon substitution for B during the low-temperature synthesis.

In the present work, carbon-coated amorphous boron powder prepared by Pavezyum company was employed as the boron precursor, with hope of providing sufficient homogeneous carbon doping for low temperature $\mathrm{Cu}$-activated $\mathrm{MgB}_{2}$ synthesis. Combining thermal analysis of the synthesis process, phase composition identification, detailed microstructure observations, and superconducting properties measurements, it was found that dense nano- $\mathrm{MgB}_{2}$ grains with a high level of homogeneous carbon doping were formed in these MgB2 samples using carbon-coated boron as a precursor that were prepared by Cu-activated sintering at low temperature. This synthesis method is responsible for the significantly improved $J_{c}$ of the present samples compared to $\mathrm{MgB}_{2}$ samples chemically doped with nano-SiC and other carbon-based dopants, with sintering at either low temperature or high temperature in previous studies [23-29]. 


\section{Experimental}

Commercial carbon-coated amorphous boron powders used in present work were from Pavezyum Advanced Chemicals (PAVEZYUM) [30]. These powders were produced through pyrolysis of a mixed gas consisting of diborane gas $\left(\mathrm{B}_{2} \mathrm{H}_{6}\right)$, hydrogen, and hydrocarbon $\left(\mathrm{C}_{x} \mathrm{H}_{y}\right)$ under inert conditions. There is always hydrogen gas present in the gas stream, which enables a reducing atmosphere and provides protection against oxidation. At the same time, it can enhance the thermal conductivity during the pyrolysis. The carbon addition is based on the simultaneous decomposition or pyrolysis of gaseous hydrocarbon $\left(\mathrm{C}_{x} \mathrm{H}_{y}\right)$ in the furnace with the $\mathrm{B}_{2} \mathrm{H}_{6}$. The temperature interval is enough to paralyze both gases, and it is thought that freshly formed spherical boron particles are coated at this stage with again freshly formed active carbon.

According to the elemental analyzers from Laboratory Equipment Corporation (LECO), the C percentage in the carbon-coated amorphous boron powder used in present work is about 2.30 wt. \%. We also investigated the microstructure of this powder by transmission electron microscopy (TEM) and electron energy loss spectroscopy (EELS) and found that the nanosize amorphous boron particles (about $50 \mathrm{~nm}$ in size) were homogeneously coated by thin layers of carbon (see Fig. 1) within the observed area. Herein, the advantage of employing this kind of carbon-coated boron as a precursor is that this thin carbon layer on the surface of the boron particle is highly active and could introduce sufficient carbon doping at low sintering temperature. Moreover, carbon doping introduced in this way should be very 
uniform.

Bulk samples of $\mathrm{MgB}_{2}$ were prepared by a Cu-activated sintering method at low temperature. Carbon-coated amorphous boron powder, Mg powder (99.5\% purity, $100 \mu \mathrm{m}$ in size), and $\mathrm{Cu}$ powder (99.7\% purity, $3 \mu \mathrm{m}$ in size) were mixed in a molar ratio of $\left(\mathrm{Mg}_{1.1} \mathrm{~B}_{2}\right) \mathrm{Cu}_{x}(x=0,0.03$ and 0.05$)$. Herein, the amount of $\mathrm{Cu}$ addition was determined according to a previous study $[15,18]$, and the excess amount of $0.1 \mathrm{Mg}$ was introduced to compensate for the oxidation of $\mathrm{Mg}$ as well as the formation of $\mathrm{Mg}-\mathrm{Cu}$ alloy during the sintering process. Then the mixed powder was pressed into cylindrical pellets $(\phi 8 \times 1.5 \mathrm{~mm})$ under a pressure of $10 \mathrm{MPa}$.

In order to acquire kinetic information during the low-temperature sintering process for the $\mathrm{Cu}$-added $\mathrm{MgB}_{2}$ using carbon-coated boron precursor, all pellets were firstly heated and analyzed simultaneously using a high-resolution Netzsch DSC 404C Differential Thermal Analysis (DTA) apparatus under protection of argon gas. A heating rate of $10^{\circ} \mathrm{C} / \mathrm{min}$ was applied from room temperature to $800^{\circ} \mathrm{C}$.

According to the differential scanning calorimetry (DSC) curves of all samples, one temperature, $600^{\circ} \mathrm{C}$, was generally selected as the sintering temperature for all the $\left(\mathrm{Mg}_{1.1} \mathrm{~B}_{2}\right) \mathrm{Cu}_{x}$ samples to fabricate the $\mathrm{MgB}_{2}$ bulks. All the samples were isothermally sintered at this temperature for $5 \mathrm{~h}$. The microstructure and phase composition of the sintered samples were examined by scanning electron microscopy (SEM) and X-ray diffraction (XRD), respectively. Based on XRD data, the lattice parameters of these prepared samples were determined by Rietveld refinement using FullProf software. The magnetization of the sintered samples was measured using a physical properties 
measurement system (PPMS). The measured cuboid samples are cut from the sintered bulks and their corresponding size is about $4 \times 2 \times 1 \mathrm{~mm}$. Then, the $T_{c}$ was obtained from the temperature dependence of the normalized zero-field-cooled (ZFC) magnetization (the applied magnetic field is $50 \mathrm{Oe}$ ), and the $J_{c}$ was calculated from the width of magnetization hysteresis loops $(\Delta M)$, based on the extended Bean model.

\section{Results and discussion}

The DSC curves of pure and $\mathrm{Cu}$ doped $\mathrm{MgB}_{2}$ samples with carbon coated amorphous boron are presented in Fig. 2 as a function of the sintering temperature. It can be seen that the sintering process for the $\mathrm{MgB}_{2}$ bulk with carbon-coated amorphous boron features two distinct exothermic peaks from room temperature to $800^{\circ} \mathrm{C}$, which is slightly different from the case of $\mathrm{MgB}_{2}$ bulks with amorphous boron in previous studies $[2,19]$. In the case of $\mathrm{MgB}_{2}$ bulks with amorphous boron, there are generally three orderly exothermic peaks corresponding to the solid-solid reaction, the melting of $\mathrm{Mg}$, and the solid-liquid reaction. Moreover, one can also see that the intensity of the first exothermic peak in these carbon-coated samples is stronger than that of a sample made with amorphous boron, accompanied by a decrease in the peaking temperature of the second exothermic peak. The explanation is that carbon-coated amorphous boron is more active than amorphous boron and can better react with solid Mg. Consequently, most of the Mg can be consumed in the solid state before it melts, and thus, no obvious peak owing to Mg melting can be recognized in the DSC curve of the carbon-coated samples in the present work. The $\left(\mathrm{Mg}_{1.1} \mathrm{~B}_{2}\right) \mathrm{Cu}_{x}$ samples with $x=$ 
0.03 and 0.05 experience a similar process to the sample without $\mathrm{Cu}$ addition, except that the peaking temperature of both exothermic peaks decreases dramatically with increasing $\mathrm{Cu}$ addition, which indicates that that $\mathrm{Cu}$ addition can also accelerate the reaction between $\mathrm{Mg}$ and carbon-coated amorphous boron to form $\mathrm{MgB}_{2}$ phase, just as in the case of $\mathrm{MgB}_{2}$ with amorphous boron, following the activated sintering mechanism [19]. This conclusion can be further confirmed by the XRD results on the corresponding $\mathrm{MgB}_{2}$ samples sintered at low temperature.

According to the DSC curves, one characteristic temperature, $600^{\circ} \mathrm{C}$, was selected as the reaction temperature to synthesize the bulk $\mathrm{MgB}_{2}$, which guarantees that $\mathrm{MgB}_{2}$ phase can form as rapidly as possible in the Cu-added samples, while the volatility of Mg can be minimized. Fig. 3 shows the XRD patterns of the $\left(\mathrm{Mg}_{1.1} \mathrm{~B} 2\right) \mathrm{Cu}_{x}(x=0$, 0.03, and 0.05) samples with carbon-coated boron prepared by sintering at $600^{\circ} \mathrm{C}$ for $5 \mathrm{~h}$. It is found that the $\mathrm{MgB}_{2}$ sample without $\mathrm{Cu}$ addition consists of $\mathrm{Mg}$ as the main phase and $\mathrm{MgB}_{2}$ as the minor phase. This result indicates that the reaction between Mg and carbon-coated boron is still very slow at such a temperature, and only a small amount of $\mathrm{MgB}_{2}$ can be formed in the carbon-coated sample without $\mathrm{Cu}$ addition. On the other hand, in the $\left(\mathrm{Mg}_{1.1} \mathrm{~B}_{2}\right) \mathrm{Cu}_{x}(x=0.03$ and 0.05$)$ samples sintered at the same temperature, $\mathrm{MgB}_{2}$ is present as the main phase with $\mathrm{MgCu}_{2}$ phase as the minor phase. Moreover, as the amount of $\mathrm{Cu}$ addition increases, the intensity of the $\mathrm{MgB}_{2}$ peaks becomes stronger. This result, consistent with the DSC results shown above, suggests that the formation of $\mathrm{MgB}_{2}$ phase in the samples where carbon-coated boron is used as precursor can be accelerated as well by $\mathrm{Cu}$ addition during the sintering process. 
Generally, carbon doping decreases the lattice parameter $a$, while it has no obvious influence on lattice parameter $c$ in the $\mathrm{MgB}_{2}$ lattice. In order to verify whether carbon doping was introduced effectively into the $\left(\mathrm{Mg}_{1.1} \mathrm{~B}_{2}\right) \mathrm{Cu}_{x}(x=0.03$ and 0.05$)$ samples with carbon-coated boron prepared in the present work, their $\mathrm{MgB}_{2}$ lattice parameters were calculated based on the XRD data. It is found that lattice parameter $a$ of these two samples is obviously decreased to $3.0731 \AA$ and $3.0712 \AA$, respectively, which are both smaller than that of standard $\mathrm{MgB}_{2}$ bulks with amorphous boron, while lattice parameter $c$ remains almost unchanged. According to Avdeev et al.'s study [31], the level of $\mathrm{C}$ substitution, $x$ in the formula $\operatorname{Mg}\left(\mathrm{B}_{1-x} \mathrm{C}_{x}\right)_{2}$ can be estimated as $x=7.5 \Delta(c / a)$, where $\Delta(c / a)$ is the change in $c / a$ compared to a pure $\mathrm{MgB}_{2}$ sample. In the present case, the actual amount of carbon doping in the $\left(\mathrm{Mg}_{1.1} \mathrm{~B}_{2}\right) \mathrm{Cu}_{0.03}$ and $\left(\mathrm{Mg}_{1.1} \mathrm{~B}_{2}\right) \mathrm{Cu}_{0.05}$ samples is $0.023 a n d 0.026$, respectively, which indicates that usage of carbon-coated boron as precursor can effectively introduce carbon doping at low temperature and that $\mathrm{Cu}$ addition can promote this process to a certain extent. Compared to other approaches that introduce carbon doping at low sintering temperature (see table 1) [24, 27, 28, 32], the level of carbon doping introduced by carbon-coated boron in present work is higher, which must be attributed to the higher activity of the carbon layer on the surface of the boron particles.

Fig. 4 shows SEM images of the microstructures of $\left(\mathrm{Mg}_{1.1} \mathrm{~B}_{2}\right) \mathrm{Cu}_{x}(x=0,0.03$ and 0.05) samples after sintering at $600^{\circ} \mathrm{C}$ for $5 \mathrm{~h}$. It is observed that the $\mathrm{MgB}_{2}$ sample without $\mathrm{Cu}$ addition that was sintered at low temperature is porous, and no regular $\mathrm{MgB}_{2}$ grains can be easily recognized (see Fig. 1a), even though highly active 
carbon-coated amorphous boron was employed as precursor. On the other hand, the $\mathrm{MgB}_{2}$ samples with $\mathrm{Cu}$ addition sintered under the same conditions consist of large amounts of uniform refined $\mathrm{MgB}_{2}$ grains. These samples are also denser than the samples without $\mathrm{Cu}$ addition because all those $\mathrm{MgB}_{2}$ grains were formed as the major component and in better connection with each other (see Fig. 4b, 4c, and 4d). Even compared to the $\mathrm{Cu}$-doped $\mathrm{MgB}_{2}$ samples with amorphous boron, or $\mathrm{Cu}$ and other carbon-based chemically co-doped $\mathrm{MgB}_{2}$ samples sintered at low temperature in previous studies [14, 27-29], the $\mathrm{MgB}_{2}$ grains in the samples prepared herein are much smaller (about 100-200 nm, see Fig. 4d) and more homogeneous. Actually, this kind of nanosize $\mathrm{MgB}_{2}$ grain can only be observed in previous studies in $\mathrm{MgB}_{2}$ samples fabricated after long ball-milling treatment of precursors and subsequent sintering [33-35]. Since the grain size of the $\mathrm{MgB}_{2}$ as it is formed depends on the particle size of the boron powder precursor [36, 37], it is easy to understand this result, given that the boron precursor in the present work, carbon-coated boron particles prepared by pyrolysis of mixed diborane $\left(\mathrm{B}_{2} \mathrm{H}_{6}\right)$, hydrogen, and hydrocarbon $\left(\mathrm{C}_{\mathrm{x}} \mathrm{H}_{\mathrm{y}}\right)$ gas, is more refined and homogeneous than amorphous boron (see Fig. 1). Moreover, the low sintering temperature in the present case can also prevent the $\mathrm{MgB}_{2}$ grain coarsening that always occurs during high temperature sintering.

The temperature dependence of the normalized ZFC magnetization for the $\left(\mathrm{Mg}_{1.1} \mathrm{~B}_{2}\right) \mathrm{Cu}_{x}(x=0,0.03$ and 0.05$)$ samples after sintering at $600^{\circ} \mathrm{C}$ for $5 \mathrm{~h}$ is presented in Fig. 5. The sample without $\mathrm{Cu}$ addition exhibits weak superconductivity due to the minor $\mathrm{MgB}_{2}$ phase. The $T_{c}$ values of $\left(\mathrm{Mg}_{1.1} \mathrm{~B}_{2}\right) \mathrm{Cu}_{0.03}$ and $\left(\mathrm{Mg}_{1.1} \mathrm{~B}_{2}\right) \mathrm{Cu}_{0.05}$ 
sintered at low temperature both appear similar to that of a traditional $\mathrm{MgB}_{2}$ sample with amorphous boron sintered at high temperature, except that there is a slight depression in $T_{c}$. This might be attributed to the $\mathrm{C}$ substitution for $\mathrm{B}$. With $\mathrm{Cu}$ addition increasing from 3at $\%$ to $5 \mathrm{at} \%$, one can see that the $T_{c}$ is slightly decreased, which should result from more $\mathrm{C}$ substitution for $\mathrm{B}$, as well as more $\mathrm{MgCu}_{2}$ impurity, existing in the 5 at\% $\mathrm{Cu}$ doped sample. The measured $J_{c}-H$ characteristics of the low-temperature sintered $\left(\mathrm{Mg}_{1.1} \mathrm{~B}_{2}\right) \mathrm{Cu}_{x}(x=0.03$ and 0.05$)$ samples are shown in Fig. 6. As references, the $J_{c}-H$ characteristics of a $\mathrm{Cu}$-doped $\mathrm{MgB}_{2}$ sample and of a $\mathrm{Cu}$ and nano-SiC multi-doped $\mathrm{MgB}_{2}$ sample are presented in Fig. 6 as well. (The multi-doped sample exhibited the best reported $J_{c}$ performance among all the low temperature sintered $\mathrm{MgB}_{2}$ samples in previous studies [29].) Both of these reference samples were made from amorphous boron precursor and subjected to low temperature sintering under the same conditions as the present $\mathrm{Cu}$-added samples made from carbon-coated amorphous boron precursor. The sample without $\mathrm{Cu}$ addition sintered under the same conditions (not shown) exhibits lower $J_{c}$ values (less than $1 \times 10^{3}$ $\mathrm{A} / \mathrm{cm}^{2}$ ), mainly due to the small fraction of $\mathrm{MgB}_{2}$ phase, and thus, the corresponding $J_{c}-H$ curve is not presented here. Although there some $\mathrm{MgCu}_{2}$ impurity exists in the $\left(\mathrm{Mg}_{1.1} \mathrm{~B}_{2}\right) \mathrm{Cu}_{0.03}$ and $\left(\mathrm{Mg}_{1.1} \mathrm{~B}_{2}\right) \mathrm{Cu}_{0.05}$ sintered at low temperature, these samples exhibit excellent $J_{c}$ (above $1 \times 10^{5} \mathrm{~A} / \mathrm{cm}^{2}$ in the $\left(\mathrm{Mg}_{1.1} \mathrm{~B}_{2}\right) \mathrm{Cu}_{0.05}$ sample at $2 \mathrm{~T}, 20 \mathrm{~K}$ ). Especially at high fields, the level of enhancement in $J_{c}$ of these two samples is much higher than those of the $\mathrm{Cu}$ and the $\mathrm{Cu}+$ nano-SiC co-doped samples, and also other carbon-based chemically doped samples sintered at low temperature [27-29, 32]. 
According to our previous studies [2, 14, 19], $\mathrm{MgCu}_{2}$ impurity mainly concentrates around the voids and is seldom embedded in the $\mathrm{MgB}_{2}$ matrix, which hardly degrades the grain connectivity of $\mathrm{MgB}_{2}$ phase and thus has no negative effect on the performance of $J_{c}$ for these two samples. Besides, higher density and less MgO impurity in our prepared samples due to low temperature sintering can obviously enhance the grain connectivity and thus further improve $J_{c}$, especially at low fields [2, 14]. More importantly, as discussed above, the level of carbon doping introduced by carbon-coated boron in present work is higher and more homogeneous than for other types of carbon-based chemical doping. Meanwhile, using carbon-coated boron as precursor can also lead to more refined $\mathrm{MgB}_{2}$ grains, which are supposed to provide more grain boundary pinning. Both factors contribute to the significantly improved $J_{c}$ at high fields. Further analysis of the flux pinning behavior in terms of flux pinning force can provide us with deeper insights. Fig. 7 shows the normalized pinning force $F_{p} / F_{\text {pmax }}$ as a function of reduced magnetic field $h$ in the as-prepared samples with $h=$ $H / H_{\text {irr }}$, where $H_{\text {irr }}$ is the irreversibility field. Flux pinning force per unit area, or pressure, $F_{p}=-J_{c} \times B$, defines $J_{c}$ in Type II superconductors and is determined by the microstructure and nanostructure of the sample. The irreversibility field $\left(H_{i r r}\right)$ has been estimated by extrapolating the $J_{c}^{1 / 2} H^{1 / 4}$ vs. $H$ curve to the horizontal axis, also called the Kramer extrapolation. According to the Hughes' study [38], if the grain boundary pinning is predominant, the peak of the $F_{p} / F_{\text {pmax }}$ is expected to be located at $h=0.2$. In the present study, the peak of $F_{p} / F_{p m a x}$ in the Cu-doped $\mathrm{MgB}_{2}$ sample with amorphous boron precursor fabricated at low temperature is located at about $h=0.2$, 
which indicates that the grain boundary pinning is the predominant pinning mechanism in this sample. On the other hand, the peak of the pinning force curves in both the nano-SiC and $\mathrm{Cu}$ co-doped $\mathrm{MgB}_{2}$ sample and the $\mathrm{Cu}$-doped $\mathrm{MgB}_{2}$ sample with carbon-coated boron sintered at low temperature are shifted towards high field, which reveals the additional pinning centers supposed to result from carbon doping. Besides, more refined $\mathrm{MgB}_{2}$ grains and nano impurities in these two samples may also contribute to the additional pinning centers. The peak in the pinning force curve for the $\mathrm{Cu}$-doped $\mathrm{MgB}_{2}$ sample with carbon-coated boron is shifted towards even higher field than that of the nano-SiC and $\mathrm{Cu}$ co-doped sample, indicating more carbon doping in this sample.

It is worth noting that the $J_{c}$ performances of the low-temperature sintered $\left(\mathrm{MgB}_{2}\right) \mathrm{Cu}_{0.03}$ and $\left(\mathrm{Mg}_{1.1} \mathrm{~B}_{2}\right) \mathrm{Cu}_{0.05}$ samples with carbon-coated boron are even better than some of carbon-based chemically doped samples sintered at high-temperature across the whole field [22-23, 25, 39]. This can be mainly attributed to the higher density and the presence of less $\mathrm{MgO}$ impurity resulting from the depressed volatility and lesser tendency of $\mathrm{Mg}$ to oxidize, respectively, during the low-temperature Cu-activated sintering. On the other hand, the value of magnetic $J_{c}$ in our prepared samples is still lower than transport $J_{c}$ in the $\mathrm{C}_{4} \mathrm{H}_{6} \mathrm{O}_{5}$ doped $\mathrm{MgB}_{2}$ wires fabricated by low temperature sintering after cold high pressure densification (CHPD), as shown in our previous study [40]. This means that the $J_{c}$ of $\left(\mathrm{Mg}_{1.1} \mathrm{~B}_{2}\right) \mathrm{Cu}_{\mathrm{x}}$ bulks and wires with carbon-coated boron precursor could be further improved in future via pressure effect, such as CHPD and hot isostatic pressure (HIP). 


\section{Conclusions}

In summary, $\mathrm{MgB}_{2}$ bulks with carbon-coated boron used as precursor were synthesized at low temperature by Cu-activated sintering. The usage of carbon-coated boron in the present work resulted in uniform refined $\mathrm{MgB}_{2}$ grains, as well as a high level of homogeneous carbon doping in the $\mathrm{MgB}_{2}$ samples. These factors, combining the advantages of the carbon-coated boron with the advantages of Cu-activated sintering at low temperature, led to significant improvement of $J_{c}$. The value of $J_{c}$ in the $\left(\mathrm{Mg}_{1.1} \mathrm{~B}_{2}\right) \mathrm{Cu}_{0.05}$ sample prepared here is even above $1 \times 10^{5} \mathrm{~A} / \mathrm{cm}^{2}$ at $2 \mathrm{~T}, 20 \mathrm{~K}$, which is higher than for other undoped and doped $\mathrm{MgB}_{2}$ samples sintered under various conditions. These results suggest that low-temperature Cu-activated sintering combined with employment of carbon-coated amorphous boron as precursor could be a promising technique to produce practical $\mathrm{MgB}_{2}$ bulks or wires with excellent $J_{c}$ on an industrial scale. This is because the carbon-coated amorphous boron powder can be produced commercially at low cost, while the addition of $\mathrm{Cu}$ is very convenient and inexpensive.

Acknowledgement This work is supported by the Australian Research Council (Grant No. DE140101333). The authors are also grateful to China National Funds for Distinguished Young Scientists (Grant No. 51325401), the National Natural Science Foundation of China (Grant No. 51302186), the Natural Science Foundation of Tianjin (Grant No. 13JCZDJC32300 and 14JCQNJC03300) and New Teachers' Fund for Doctor Stations, Ministry of Education (Grant No. 2012003212001). 


\section{References}

[1]J. Nagamatsu, N. Nakagawa, T. Muranaka, Y. Zentani and J. Akimitsu, Nature, 410 63-64 (2001).

[2] Z. Q. Ma and Y. C. Liu, Int. Mater. Rev., 56 267-286 (2011).

[3] G. Z. Li, M. D. Sumption, M. A. Susner, Y. Yang, K. M. Reddy, M. A. Rindfleisch, M. J. Tomsic, C. J. Thong and E. W. Collings, Supercond. Sci. Technol. 25115023 (2012).

[4] A. Yamamoto, J. Shimoyama, S. Ueda, Y. Katsura, S. Horii and K. Kishio, Supercond. Sci. Technol., 18 116-121 (2005).

[5] N. Rogado, M. A. Hayward, K. A. Regan, Y. Wang, N. P. Ong, H. W. Zandbergen, J. M. Rowell and R. J. Cava, J. Appl. Phys., 91 274-277 (2002).

[6]A. Yamamoto, J. Shimoyama, S. Ueda, Y. Katsura, I. Iwayama, S. Horii and K. Kishio, Physica C, 445-448 801-805 (2006).

[7] Z. Q. Ma and Y. C. Liu, Mater. Chem. Phys., 126 114-117 (2011).

[8] H. Fujii, K. Togano and H. Kumakura, Supercond. Sci. Technol., 15 1571-1576 (2002).

[9]C. Chen, Z. J. Zhou, X. G. Li, J. Xu, Y. H. Wang, Z. X. Gao and Q. R. Feng, Solid State Commun.,131 275-278 (2004).

[10]H. Yamada, M. Hirakawa, H. Kumakura, A Matsumoto and H. Kitaguchi, Appl. Phys. Lett., 84 1728-1730 (2004).

[11] J. Shimoyama, K. Hanafusa, A. Yamamoto, Y. Katsura, S. Horii, K. Kishio and H. Kumakura, Supercond. Sci. Technol., 20 307-311 (2007). 
[12]W. J. Feng, T. D. Xia, T. Z. Liu, W. J. Zhao and Z. Q. Wei, Physica C, 425 144-148 (2005).

[13] Y. Hishinuma, A. Kikuchi, Y. Iijima, Y. Yoshida, T. Takeuchi and A. Nishimura, IEEE Trans. Appl. Supercond., 17 2798-2801 (2007).

[14] Z. Q. Ma, Y. C. Liu, Q. Z. Shi, Q. Zhao and Z. M. Gao, Supercond. Sci. Technol., 21065004 (2008).

[15]Y. Hishinuma, A. Kikuchi and T. Takeuchi, Supercond. Sci. Technol., 20 1178-1183 (2007).

[16]J-C Grivel, A. Abrahamsen and J. Bednarckk, Supercond. Sci. Technol., 21 035006 (2008).

[17] M. Woźniak, K. L. Juda, S.C. Hopkins, D. Gajda and B. A. Glowacki, Supercond. Sci. Technol. 26105008 (2013).

[18] Z. Q. Ma, Y. C. Liu, Y. J. Han, Q. Zhao and Z. M. Gao, J. Appl. Phys., 104 063917 (2008).

[19] Z. Q. Ma, Y. C. Liu, Q. Z. Shi, Q. Zhao and Z. M. Gao, Mater. Res. Bull., 44 531-537(2009).

[20] Z. Q. Ma, Y. C. Liu, Q. Z. Shi, Q. Zhao and Z. M. Gao, Physica C, 468 2250-2253 (2008).

[21] C. M. Kipphut and R. M. German, Sci. Sintering, 20 31-41 (1988).

[22]S. Zhou, A. V. Pan, D. Wexler and S. X. Dou, Adv. Mater., 19 1373-6 (2007).

[23] S. X. Dou, S. Soltanian, J. Horvat, X. L. Wang, S. H. Zhou, M. Ionescu and H. K. Liu, Appl. Phys. Lett., 81 3419-21 (2002). 
[24] S. P. Tang, D. L. Wang, X. P. Zhang, Q. J. Zhang, C Li, Y. W. Ma, H. Oguro, S. Awaji, K. Watanabe, J Supercond. Nov. Magn., 27 2699-2705 (2014).

[25] J.H. Kim, X. Xu, M.S.A. Hossain, D.Q. Shi, Y. Zhao, X. L. Wang, S. X. Dou, S. Choi and T. Kiyoshi, Appl. Phys. Lett., 92042506 (2008).

[26] A. Yamamoto, J. Shimoyama, S. Ueda, S. Horii, K. Kishio, IEEE Trans. Appl. Supercond. 16 1411-1414 (2006).

[27] M. S. A. Hossain, J. H. Kim, X. Xu, X. L. Wang, M. Rindfleisch, M. Tomsic, M. D. Sumption, E. W. Collings and S. X. Dou, Supercond. Sci. Technol., 20 L51-L54 (2007).

[28] Q. Cai, Y. C. Liu, Z. Q. Ma, L. M. Yu, J. Xiong, H. J. Li, Journal of Alloys and Compounds 585 78-84 (2014).

[29] Z. Q. Ma, Y. C. Liu, W. P. Hu, Z. M. Gao, L. M. Yu and Z. Z. Dong, Scripta Mater., 61 836-839 (2009).

[30] http://pavezyum.com.tr/

[31] M. Avdeev, J. D. Jorgensen, R. A. Ribeiro, S. L. Bud'ko and P. C. Canfield, Physica C, 387 301-306 (2003).

[32] S. K. Chen, K. Y. Tan, A. S. Halim, X. Xu, K. S. B. De Silva, W. K. Yeoh, S. X. Dou, A. Kursumovic and J. L. MacManus-Driscoll, Supercond. Sci. Technol. 26125018 (2013).

[33] Y. D. Gao, J. Ding, Q. Chen, G. V. S. Rao and B. V. R. Chowdari, Acta Mater., 52 1543 (2004).

[34] M. Herrmann, W. Häßler, C. Rodig, W. Gruner, B. Holzapfel and L. Schultz, 
Appl. Phys. Lett., 91082507 (2007).

[35] Z. Q. Ma, Y. C. Liu, J. Huo and Z. M. Gao, J. Appl. Phys., 106113911 (2009).

[36] S. K. Chen, K. A. Yates, M. G. Blamire and J. L. MacManus-Driscoll, Supercond.

Sci. Technol., 181473 (2005).

[37] W. Hassler, B. Birajdar, W. Gruner, M. Herrmann, O. Perner, C. Rodig, M.

Schubert, B. Holzapfel, O. Eibl and L. Schultz, Supercond. Sci. Technol., 19512 (2006).

[38] D. Hughes, Philos. Mag. B, 55459 (1987).

[39] J. H. Lim, S. H. Jang, S. M. Hwang, J. H. Choi, J. Joo, W. N. Kang and C. Kim, Physica C, 468 1829-1832 (2008).

[40] M. S. A. Hossain, C. Senatore, R. Flukiger, M. A. Rindfleisch, M. J. Tomsic, J. H. Kim and S. X. Dou, Supercond. Sci. Technol. 22095004 (2009). 


\section{Table and Figure captions}

Table 1 Comparasion of actual carbon doping level and $J_{c}$ among low temperature sintered $\mathrm{MgB}_{2}$ samples using various carbon doping methods.

Fig. 1 TEM images of carbon-coated nanosize amorphous boron particles prepared by the pyrolysis technique.

Fig. 2 DSC curves of pure and Cu-doped $\mathrm{MgB}_{2}$ samples with carbon coated amorphous boron. The DSC curve of undoped $\mathrm{MgB}_{2}$ samples with amorphous boron was also present as a reference.

Fig. 3 XRD patterns of the $\left(\mathrm{Mg}_{1.1} \mathrm{~B}_{2}\right) \mathrm{Cu}_{x}(x=0,0.03$ and 0.05$)$ samples with carbon-coated boron prepared by sintering at $600^{\circ} \mathrm{C}$ for $5 \mathrm{~h}$.

Fig. 4 SEM images of the microstructures of $\left(\mathrm{Mg}_{1.1} \mathrm{~B}_{2}\right) \mathrm{Cu}_{x}(x=0,0.03$ and 0.05$)$ samples with carbon-coated boron after sintering at $600^{\circ} \mathrm{C}$ for $5 \mathrm{~h}$, with (a) $\mathrm{Mg}_{1.1} \mathrm{~B}_{2}$, (b) $\left(\mathrm{Mg}_{1.1} \mathrm{~B}_{2}\right) \mathrm{Cu}_{0.03}$ and (c) $\left(\mathrm{Mg}_{1.1} \mathrm{~B}_{2}\right) \mathrm{Cu}_{0.05}$. High-resolution SEM image of $\left(\mathrm{Mg}_{1.1} \mathrm{~B}_{2}\right) \mathrm{Cu}_{0.05}$ sample is also presented in (d) to allow better observation of $\mathrm{MgB}_{2}$ grains in the $\mathrm{Cu}$-doped sample.

Fig. 5 Temperature dependence of normalized ZFC magnetization for the $\left(\mathrm{Mg}_{1.1} \mathrm{~B}_{2}\right) \mathrm{Cu}_{x}(x=0,0.03$ and 0.05$)$ samples with carbon coated boron after sintering at $600^{\circ} \mathrm{C}$ for $5 \mathrm{~h}$.

Fig. 6 Measured $J_{c}-H$ characteristics of the low-temperature sintered $\left(\mathrm{Mg}_{1.1} \mathrm{~B}_{2}\right) \mathrm{Cu}_{x}(x$ $=0.03$ and 0.05 ) samples with carbon coated boron at $20 \mathrm{~K}$. The inset is $J_{c}-H$ characteristics of these two samples measured at $4.2 \mathrm{~K}$. Besides, the $J_{c}-H$ characteristics of a both $\mathrm{Cu}$ and nano-SiC multi-doped $\mathrm{MgB}_{2}$ sample and of a solely 
$\mathrm{Cu}$ doped sample, both made with amorphous boron precursor and sintered under the same conditions, are also presented here as references.

Fig. 7 Normalized pinning force $F_{p} / F_{p \max }$ as a function of reduced magnetic field $h$ for the low-temperature sintered $\left(\mathrm{Mg}_{1.1} \mathrm{~B}_{2}\right) \mathrm{Cu}_{0.03}$ sample, with $h=H / H_{\text {irr }}$. The corresponding $F_{p} / F_{\text {pmax }}$ curves of both the $\mathrm{Cu}$ and nano $\mathrm{SiC}$ multi-doped $\mathrm{MgB}_{2}$ sample and the solely $\mathrm{Cu}$ doped sample, both with amorphous boron precursor sintered under the same conditions, are also presented as references. 
Table 1

\begin{tabular}{|c|c|c|c|}
\hline samples & $\begin{array}{l}\text { sintering } \\
\text { condition }\end{array}$ & $\begin{array}{c}x \text { in } \\
\operatorname{Mg}\left(B_{1-x} C_{x}\right)_{2}\end{array}$ & $\begin{array}{c}J_{c}(20 \mathrm{~K}, 2 \mathrm{~T}) \\
\mathrm{A} / \mathrm{cm}^{2}\end{array}$ \\
\hline $\begin{array}{l}\mathrm{MgB}_{2}+8 \text { at\% graphene } \\
\text { Solid state mixing [24] }\end{array}$ & $650^{\circ} \mathrm{C}, 5 \mathrm{~h}$ & 0.023 & $8.7 \times 10^{4}$ \\
\hline $\begin{array}{c}\text { MgB2 + } 3 \text { wt } \% \text { SiC } \\
\text { Solid state mixing [32] }\end{array}$ & $650^{\circ} \mathrm{C}, 1 \mathrm{~h}$ & 0.010 & $5.5 \times 10^{4}$ \\
\hline $\begin{array}{l}\mathrm{MgB}_{2}+10 \text { at } \% \mathrm{C}_{4} \mathrm{H}_{6} \mathrm{O}_{5} \\
\text { Chemical solution [27] }\end{array}$ & $600^{\circ} \mathrm{C}, 4 \mathrm{~h}$ & 0.023 & $4.5 \times 10^{4}$ \\
\hline $\begin{array}{c}\text { (MgB2)0.97Cu0.03 + } 3 \text { wt\% Gly } \\
\text { Chemical solution [28] }\end{array}$ & $600^{\circ} \mathrm{C}, 15 \mathrm{~h}$ & 0.019 & $3.9 \times 10^{4}$ \\
\hline $\begin{array}{c}\left(\mathrm{Mg}_{1.1} \mathrm{~B}_{2}\right) \mathrm{Cu}_{0.05} \text { with carbon coated } \\
\text { boron precursor this work }\end{array}$ & $600^{\circ} \mathrm{C}, \quad 5 \mathrm{~h}$ & 0.026 & $1.02 \times 10^{5}$ \\
\hline
\end{tabular}


Fig. 1
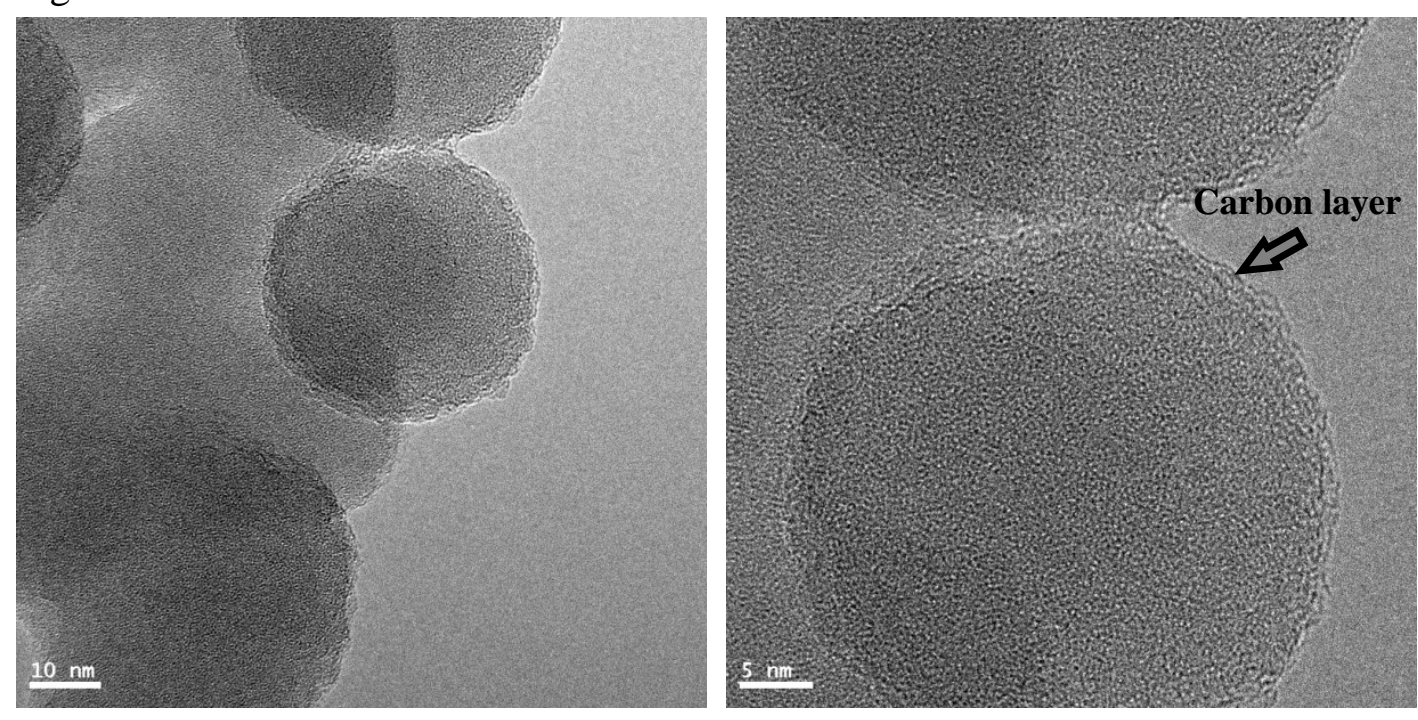

Fig. 2

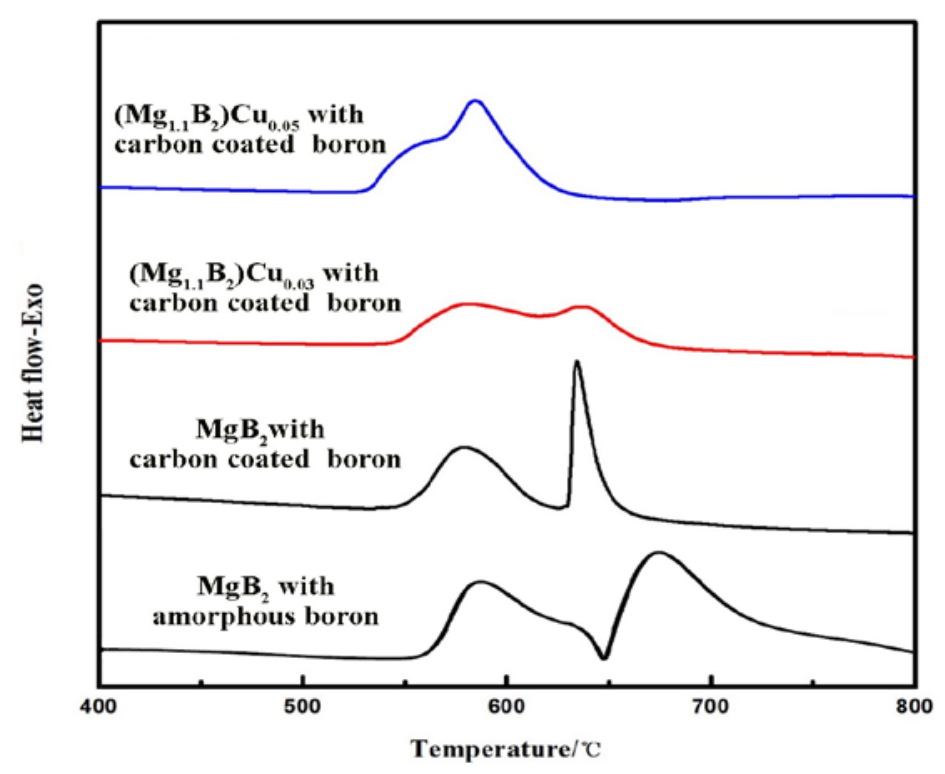


Fig. 3

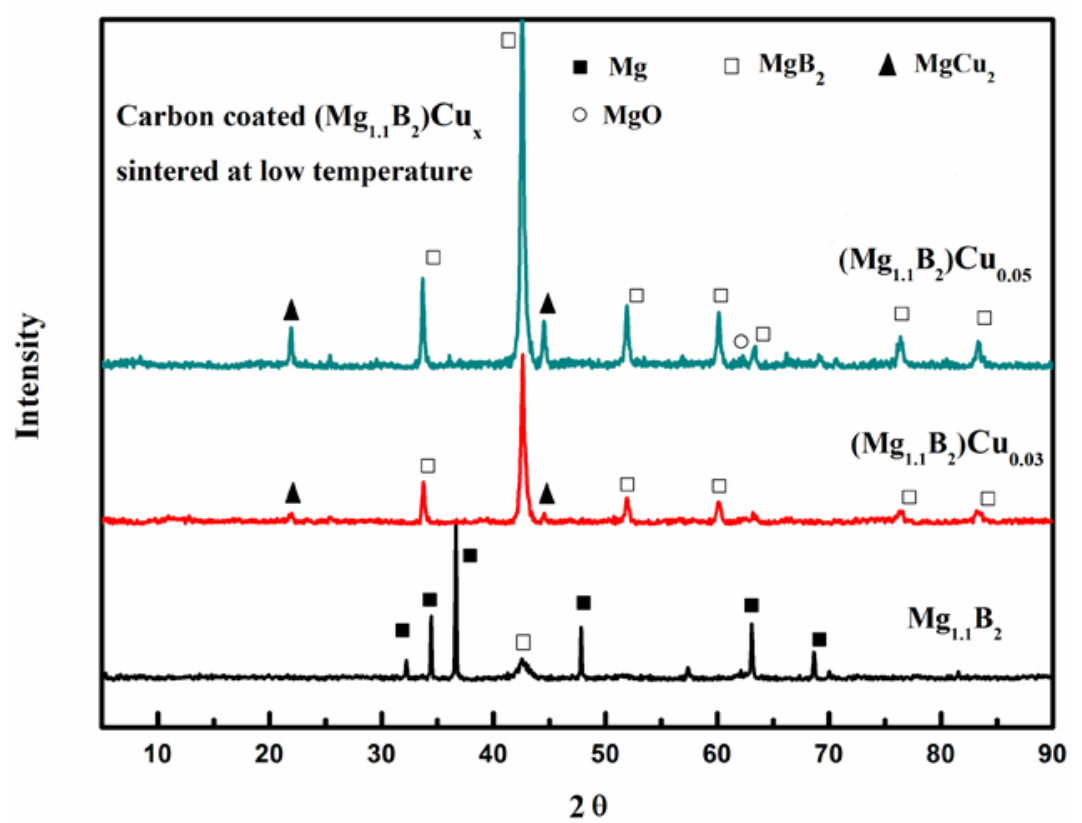

Fig. 4
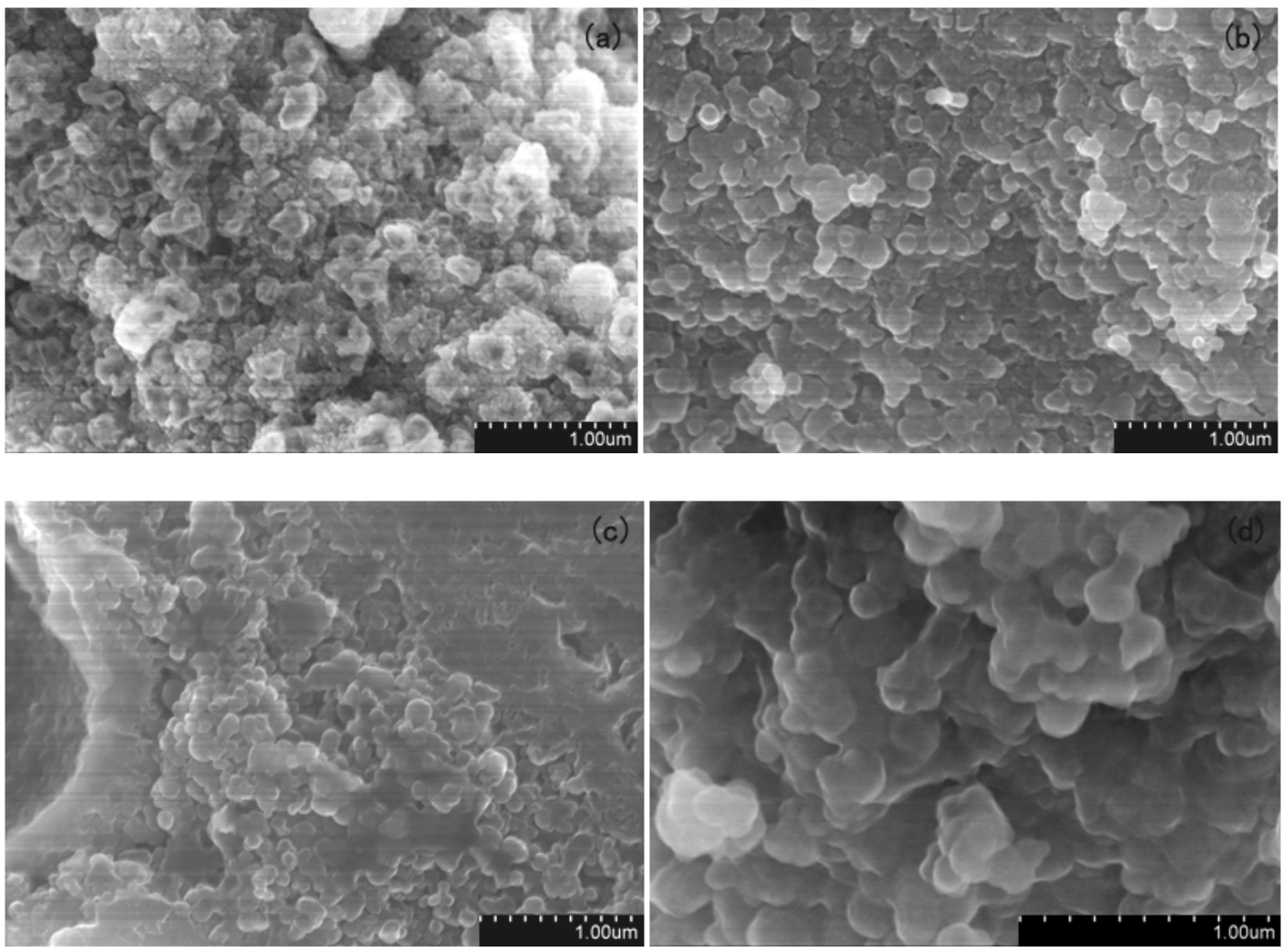
Fig. 5

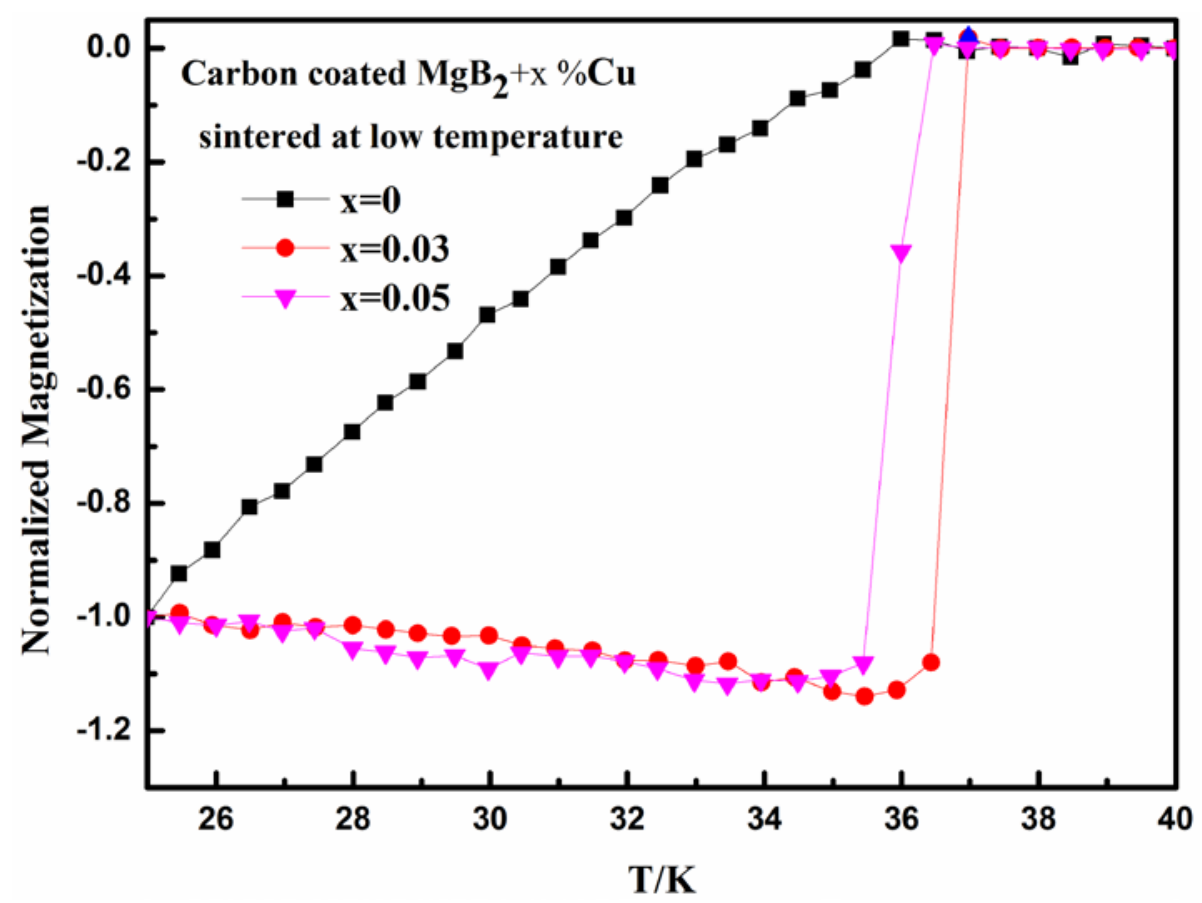

Fig. 6

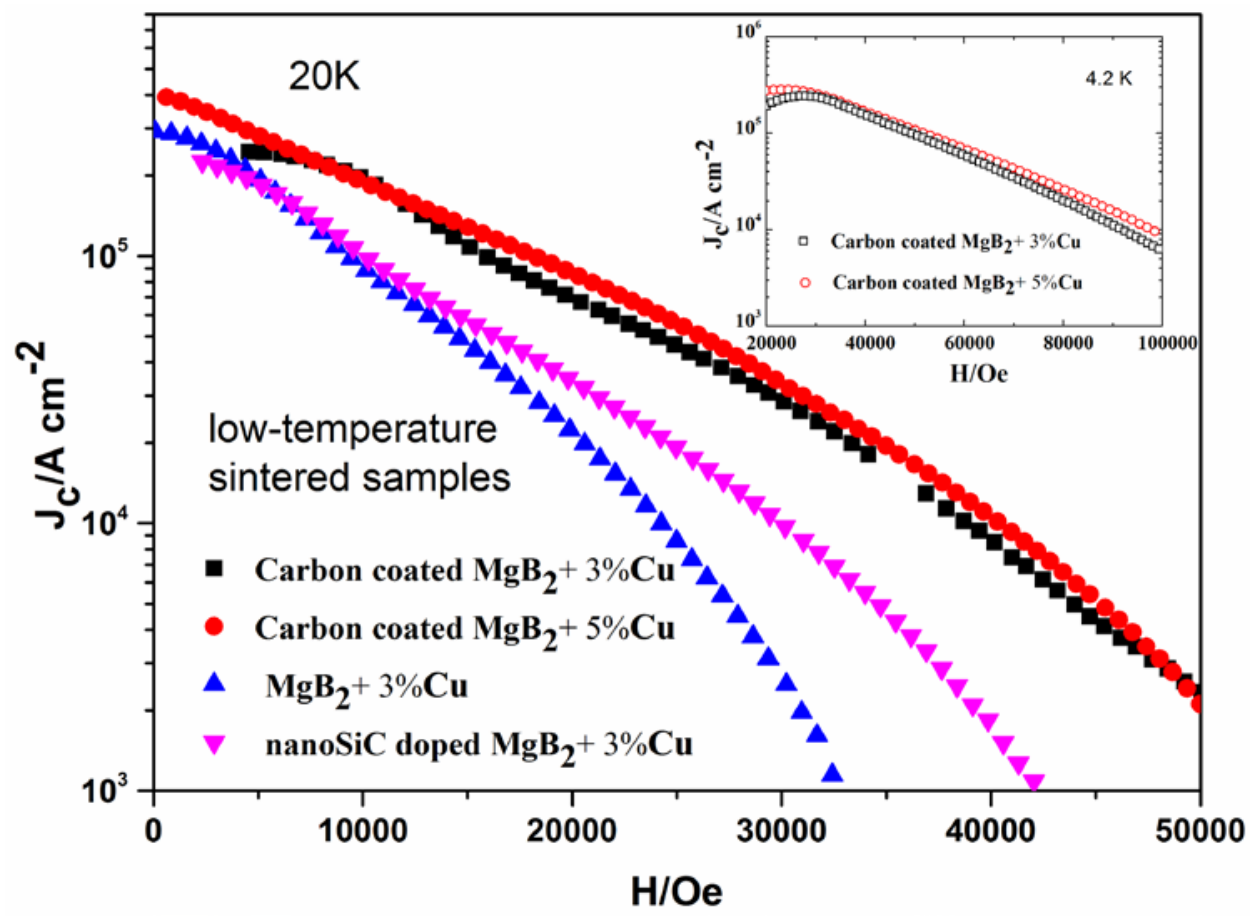


Fig. 7

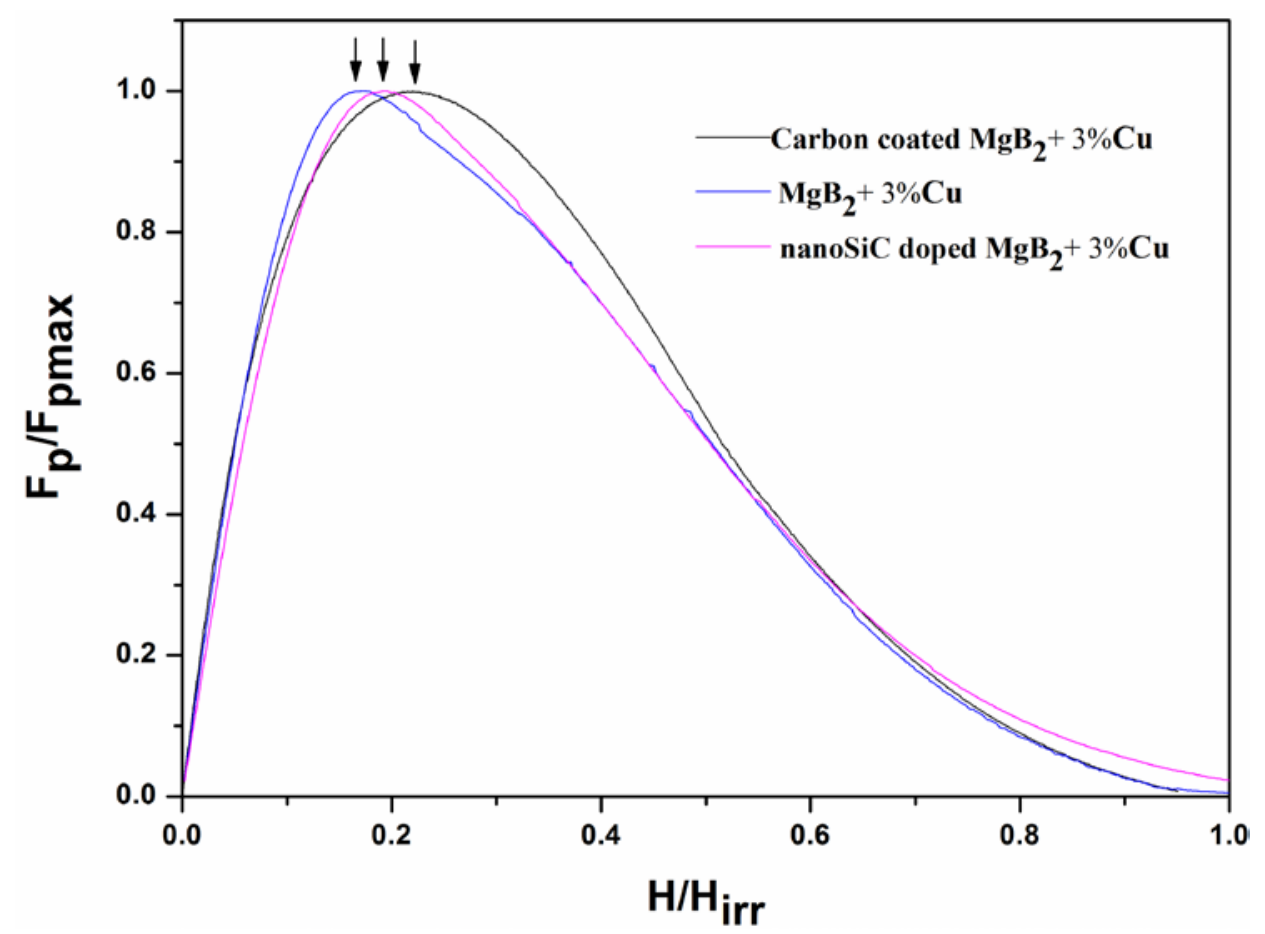

